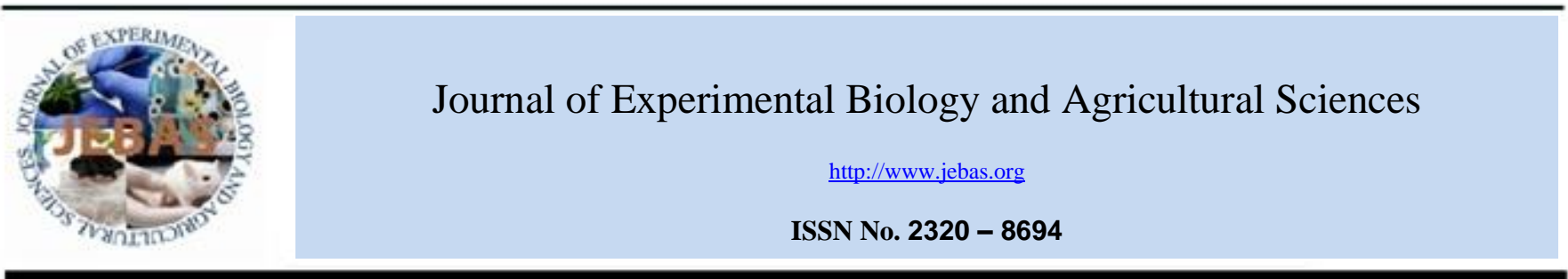

\title{
OPTIMIZATION OF NATURAL DYE EXTRACTION FROM COCONUT HUSK
}

\section{Indrajeet A Samant, D. K. Gaikwad}

Department of Botany, Shivaji University, Kolhapur 416004, Maharashtra, India.

Received - November 15, 2019; Revision - December 30, 2019; Accepted - February 05, 2020

Available Online - February 25, 2020

DOI: http://dx.doi.org/10.18006/2020.8(1).54.62

\section{KEYWORDS}

Dye yield

RSM

Box-Behnken approach

Fibrous husk

\begin{abstract}
Coconut is used throughout worldwide in various rituals, festivals and in food. A huge amount of unused parts of coconut such as fibrous husk and shells are thrashed every day. The present study illustrates the sustainable use of fibrous husk as a source of natural dye. Hence, in order to improve the dye yield, various dye extracting factors were optimized with the help of statistical software. The RSM based Box Behnken approach for optimization was found effective which increases dye yield up to $37 \%$. The analysis of the model implies that the model fits well for all the four factors and found to be significant. All the factors $\mathrm{M}$ : L ratio, temperature, Time and $\mathrm{pH}$ were found influential in the dye extracting process. The system also helps to improve the yield for desired $\mathrm{pH}$ to obtain multiple hues. The optimized parameters to improve dye yield were $\mathrm{M}: \mathrm{L}$ ratio of $1: 130$, temperature $80^{\circ} \mathrm{C}$, time 250 minutes, $\mathrm{pH} 9.3$.
\end{abstract}

* Corresponding author

E-mail: indrajeetsamant1103@gmail.com (Indrajeet. A. Samant)

Peer review under responsibility of Journal of Experimental Biology and Agricultural Sciences.

Production and Hosting by Horizon Publisher India [HPI] (http://www.horizonpublisherindia.in/).

All rights reserved.
All the articles published by Journal of Experimental Biology and Agricultural Sciences are licensed under a Creative Commons Attribution-NonCommercial 4.0 International License Based on a work at www.jebas.org.

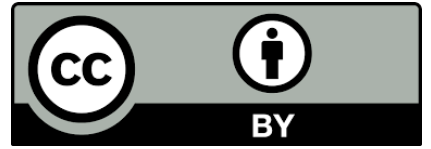




\section{Introduction}

Natural colors are dyes or pigments acquired from plants, animals or mineral resources without any chemical preparations. They are produced from sources such as fruits, leaves, flowers, roots, barks, insects, etc. Indeed, they are not easily accessible and require an appropriate extraction method. Modern day synthetic dyes marked by Perkin's invention of mauve in 1856 , leads to the decline of natural dyes (Zollinger, 2003). Most synthetic dyes are carcinogenic and can cause allergic reactions. While natural dyes impart several benefits over synthetic colors as they are ecofriendly, non-toxic, biodegradable, aesthetically pleasing and having multiple medicinal properties (Gupta et al., 2004).

Cocos nucifera L (Family Arecaceae), often referred to as 'coconut' is regarded as a major plant in tropical and subtropical areas (Imo et al., 2018). Fruits of coconut is consumed as a nutritional diet while nonconsumable Coir fiber and husk (mesocarp) are considered as agricultural and domestic waste (Khalid Thebo et al., 2016). These natural wastes are cheaper, in toxic, extremely efficient and easily available. Thus, applying waste products as natural dyes can reduce the cost of natural dyeing and also helps in maintaining the environment.

The heavy, fibrous, and dry-tanned mesocarp has many industrial uses. Industry uses pith husk fiber as raw material for carpets, stuffing seats for cushioning, and as fertilizers in agriculture (Verma et al., 2019). The plant is commonly being used in the food industry and the use of thrown away parts of the plant will help lower waste and pollution. The fiber exhibited antibacterial, anti-inflammatory and anti-parasitic activity (Lima et al., 2015). Tea prepared from C.nucifera husk fiber is used in Brazil to treat diarrhea (Esquenazi et al., 2002). Likewise, the husk fiber extract in Guatemala is used as an antipyretic to decrease renal inflammation and as an ointment for dermatitis, abscesses, and injuries (Cáceres et al., 1987). Aqueous extract of husk fiber is used as an asthma treatment (Hope et al., 1993). Diabetes is treated by husk extract in Jamaica (Mitchell \& Ahmad, 2006). Peruvians orally use the aqueous extract of fresh coconut fiber for asthma, diuretics, and gonorrhea (Lima et al., 2015). Presence of polyphenols such as catechins, flavonoids and tannins were reported in high quantity in ethyl acetate extract (Matos, 1997; Freitas et al., 2011; Pal et al., 2011; Renjith et al., 2013). South Indian people utilize fibrous husks for brushing the teeth is a common dental care practice of many rural individuals.

Optimization of the process is an important task to improve the extraction efficiency of dye from the material. The response surface methodology (RSM) a statistical approach to the optimization method is better as it requires a lesser number of experiments compared to the full-factorial or (OFAT) one factor at a time (Sundari, 2015; Ali et al., 2016; Jabeen et al., 2019). Box-Behnken design is a very effective method optimization model fitting (RSM) tool (Tayeb et al., 2018). It also checks the adequacy of the model by finding interactions between inputs and outputs for recognizing optimum conditions. One of the benefits of this model is that this doesn't include all the variables at its extreme limit, so we can prevent experiments that may not give anticipated outcomes (Sundari, 2015). However, to the utmost of our understanding, there is almost no information on optimizing the conditions of natural dye extraction from C. nucifera. So, in this research, the effect of multiple process factors such as extraction time, $\mathrm{pH}$, temperature, material to liquor ratio (M:L) on percent production output was evaluated using Box-Behnken design.

\section{Materials and Methods}

Based on previous research findings and subsequent trials, current study identified that pre-soaking and ultrasonification of material prior to conventional simple boiling method improves production yield.

\subsection{Preparation and extraction of colorant}

Coconut husk along with its coir fiber was collected as a waste material from temples and household use. The collected material was ground in a commercial pulverizer to produce in powder form. Further, the powder was sieved to get $0.25 \mathrm{~mm}$ fine powder which was used for extraction purposes. The extraction process was carried out by taking $1 \mathrm{gm}$ of $0.25 \mathrm{~mm}$ fine powder in $500 \mathrm{ml}$ conical flask containing 100 $\mathrm{ml}$ distilled water in 1:100 ratio at $\mathrm{pH} 7$ was kept for soaking for 24 hours, after soaking it was subjected for $10 \mathrm{~min}$ ultrasonification and placed in the water bath at $90^{\circ} \mathrm{C}$ for $120 \mathrm{~min}$. The flask was covered and stirred manually by frequent shaking to prevent the wasting of solvent by evaporating. The sample was filtered and stored under cool temperature $0^{\circ}-4^{\circ} \mathrm{C}$. The same method is implied for all the 29 combinations with four different factors and their three levels which are generated by the system as given in table 1 . The extracted crude dye specimens are then transferred to a pre-weighted evaporating dish and subjected to drying at $50^{\circ} \mathrm{C}$ on a water bath until all solvent is evaporated and dried powder is formed. This powder is then cooled and weighed to determine the extracted dye weight and used to calculate the percentage of the color yield as follows (Sundari, 2015).

$$
\% \text { yeild }=\frac{W f-W i}{W p} \times 100
$$

Were, $W p$ - Weight of raw plant material; $W i$ - Initial weight of the empty evaporating dish; $W f$ - Final weight of dried natural dye with the evaporating dish.

\subsection{Optimization of the process:}

Response surface methodology (RSM) identifies optimum process configurations to attain maximum efficiency and also reduces the number of trails. Therefore, by using Design-Expert software (version 11.1.2 .Stat-Ease Inc., Minneapolis, USA), a Box-Behnken approach for four variables was selected as the design of the experiment. The percentage yield of dye was chosen as a system response whereas the 
four process parameters such as time, $\mathrm{pH}$, temperature and material to liquor ratio (M: L) were taken as input variables (Sundari, 2015). On the basis of previous trails, the lower and upper limits of each factor (time varying from 120 minutes to 300 minutes, $\mathrm{pH} 4$ to 10 , temperature $50^{\circ} \mathrm{C}$ to $90^{\circ} \mathrm{C}$ and $\mathrm{M}: \mathrm{L}$ ratio ranging from 1:100 to 1:200) were inputted in the model as shown in table 2. The combinations and the number of runs are depended upon the number of factors and their center points per block. Here, 29 runs of different combinations were generated and the optimized results were calculated. Regression analysis and Analysis of variance (ANOVA) were performed with the quadratic model by design expert software to satisfy the system generated mathematical model. Notable conditions were discovered in the model for response by analysis of variance and the importance was assessed by the F-value calculated from the data.

\section{Result and discussion:}

The 2nd-order quadratic model was equipped to correlate the connection between independent and dependent (yield) factors to predict the optimum values. The four-factor equation is indicated as follows:

$$
\begin{aligned}
\% \text { dye Yield }= & 31.47+0.236667 A+3.735 B+4.40583 C+6.9925 D \\
& +(-0.02 A B)+(-0.3425 A C)+(-0.7325 A D)+0.135 \\
& B C+1.895 B D+2.565 C D+\left(-2.81167 A^{2}\right)+ \\
& \left(-7.34167 B^{2}\right)+\left(-4.42792 C^{2}\right)+\left(-2.69542 D^{2}\right)
\end{aligned}
$$

The F-value of 26.33 stated that the model Box-Behnken design depicts significant extracted dye yield as shown in Table 3 . The terms B, C, D, CD A ${ }^{2}, \mathrm{~B}^{2}, \mathrm{C}^{2}$ and $\mathrm{D}^{2}$ are significant, since the resulted $P$ value which is below 0.05 states that the model and terms are of statistical significance. The model's adequacy and fitness are calculated using the correlation coefficient $\left(\mathrm{R}^{2}\right)$ and by the adjusted $\mathrm{R}^{2}$ values. The $\mathrm{R}^{2}$ value of 0.9634 ensures that the experimental data is compatible with the regression model. The Predicted $\mathrm{R}^{2}$ of 0.8306 is in reasonable agreement with the Adjusted $\mathrm{R}^{2}$ of 0.9268 ; i.e. the difference is less than 0.2 , this indicates a decent correlation between predicted and actual value. The adequate precision of 18.6432 shows that the signal-to-noise ratio is adequate as the values above 4 are considered normal. Furthermore, the F-value for the lack of fit is 1.09 which is non-significant relative to the pure error value as shown Table 3. The $8.16 \%$ as the observed (CV) correlation of coefficient illustrates that the deviation is below $10 \%$ indicates a decent response model (Segurola et al., 1999).

\subsection{Model adequacy check:}

The diagnostics plots obtained by the system for dye extraction optimization were used for the validation of the Box-Behnken model to prevent incorrect and misleading outcomes. The adequacy of Box Behnken regression model for prediction is assessed in diagnostic plots shown in figure 1 (A, B and C). The figure $1 \mathrm{~A}$, denotes a plot of

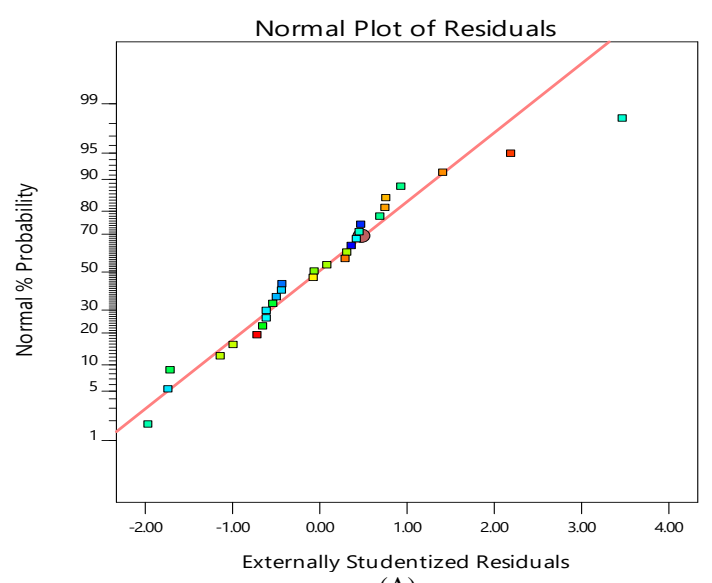

(A)

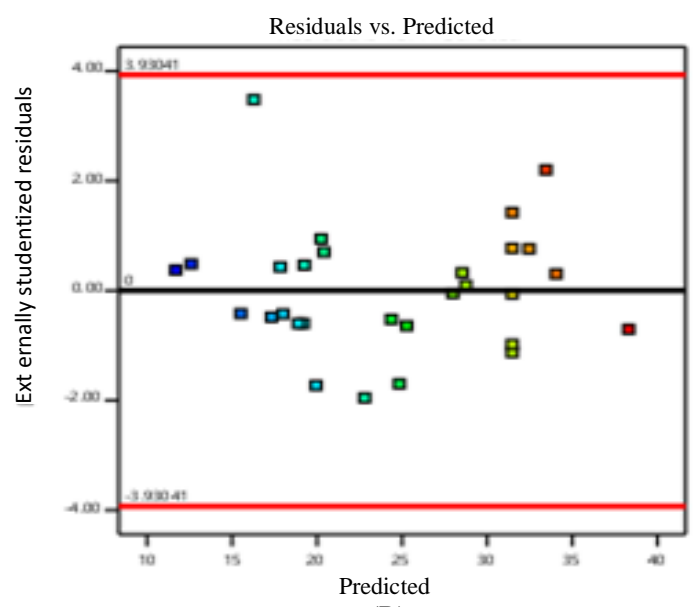

(B)

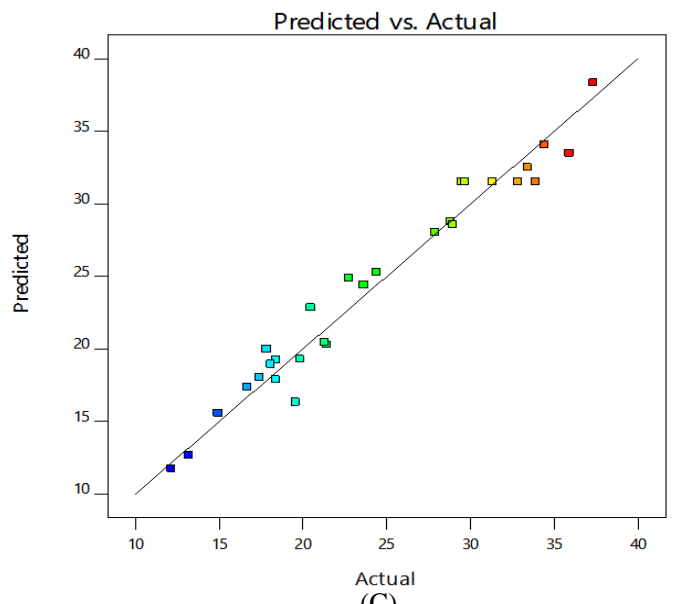

(C)

Figure 1 Diagnostic plots validating the model for optimization (A) Normal plot of residuals (B) Residual vs. predicted values, (C) predicted and actual values 
Table 1 Four factorial and Three-level experimental design and Response \% Dye yield

\begin{tabular}{|c|c|c|c|c|c|c|}
\hline Std & Run & $\begin{array}{c}\text { M:L ratio } \\
\text { (g:ml) }\end{array}$ & $\begin{array}{c}\text { Temperature } \\
\left({ }^{\circ} \mathrm{C}\right)\end{array}$ & $\begin{array}{l}\text { Time } \\
(\mathrm{min})\end{array}$ & $\mathrm{pH}$ & $\begin{array}{c}\text { Response } \\
\text { Dye Yield \% }\end{array}$ \\
\hline 14 & 1 & 150 & 90 & 120 & 7 & 18.11 \\
\hline 26 & 2 & 150 & 70 & 210 & 7 & 33.91 \\
\hline 9 & 3 & 100 & 70 & 210 & 4 & 17.44 \\
\hline 25 & 4 & 150 & 70 & 210 & 7 & 29.49 \\
\hline 5 & 5 & 150 & 70 & 120 & 4 & 14.96 \\
\hline 15 & 6 & 150 & 50 & 300 & 7 & 21.45 \\
\hline 24 & 7 & 150 & 90 & 210 & 10 & 34.46 \\
\hline 7 & 8 & 150 & 70 & 120 & 10 & 23.68 \\
\hline 22 & 9 & 150 & 90 & 210 & 4 & 19.61 \\
\hline 3 & 10 & 100 & 90 & 210 & 7 & 22.79 \\
\hline 19 & 11 & 100 & 70 & 300 & 7 & 28.87 \\
\hline 23 & 12 & 150 & 50 & 210 & 10 & 20.51 \\
\hline 16 & 13 & 150 & 90 & 300 & 7 & 27.91 \\
\hline 28 & 14 & 150 & 70 & 210 & 7 & 31.36 \\
\hline 10 & 15 & 200 & 70 & 210 & 4 & 17.87 \\
\hline 21 & 16 & 150 & 50 & 210 & 4 & 13.24 \\
\hline 27 & 17 & 150 & 70 & 210 & 7 & 32.86 \\
\hline 4 & 18 & 200 & 90 & 210 & 7 & 24.43 \\
\hline 6 & 19 & 150 & 70 & 300 & 4 & 18.41 \\
\hline 20 & 20 & 200 & 70 & 300 & 7 & 28.96 \\
\hline 17 & 21 & 100 & 70 & 120 & 7 & 19.86 \\
\hline 8 & 22 & 150 & 70 & 300 & 10 & 37.39 \\
\hline 2 & 23 & 200 & 50 & 210 & 7 & 18.41 \\
\hline 1 & 24 & 100 & 50 & 210 & 7 & 16.69 \\
\hline 18 & 25 & 200 & 70 & 120 & 7 & 21.32 \\
\hline 29 & 26 & 150 & 70 & 210 & 7 & 29.73 \\
\hline 12 & 27 & 200 & 70 & 210 & 10 & 33.45 \\
\hline 11 & 28 & 100 & 70 & 210 & 10 & 35.95 \\
\hline 13 & 29 & 150 & 50 & 120 & 7 & 12.19 \\
\hline
\end{tabular}

Table 2 Experimental factors and Levels used in current study

\begin{tabular}{|lcccc|}
\hline \multicolumn{2}{|c|}{ Factors } & \multicolumn{1}{c}{ Levels } & 1 \\
\hline M:L ratio, g:ml & (A) & $1: 100$ & 0 & $1: 200$ \\
\hline Tempreture, ${ }^{\circ} \mathrm{C}$ & (B) & $50^{\circ} \mathrm{C}$ & $1: 150$ & $90^{\circ} \mathrm{C}$ \\
\hline Time, $\min$ & (C) & 120 & $70^{\circ} \mathrm{C}$ & 300 \\
\hline $\mathrm{pH}$ & (D) & 4 & 210 & 10 \\
\hline
\end{tabular}


Table 3 ANOVA for Quadratic model

\begin{tabular}{|c|c|c|c|c|c|c|}
\hline Source & Sum of Squares & $\mathrm{df}$ & Mean Square & F-value & p-value & \\
\hline Model & 1452.35 & 14 & 103.74 & 26.33 & $<0.0001$ & significant \\
\hline A-M:L ratio & 0.6721 & 1 & 0.6721 & 0.1706 & 0.6859 & \\
\hline B-Temperature & 167.40 & 1 & 167.40 & 42.48 & $<0.0001$ & \\
\hline C-Time & 232.94 & 1 & 232.94 & 59.12 & $<0.0001$ & \\
\hline D-pH & 586.74 & 1 & 586.74 & 148.91 & $<0.0001$ & \\
\hline $\mathrm{AB}$ & 0.0016 & 1 & 0.0016 & 0.0004 & 0.9842 & \\
\hline $\mathrm{AC}$ & 0.4692 & 1 & 0.4692 & 0.1191 & 0.7352 & \\
\hline $\mathrm{AD}$ & 2.15 & 1 & 2.15 & 0.5447 & 0.4727 & \\
\hline $\mathrm{BC}$ & 0.0729 & 1 & 0.0729 & 0.0185 & 0.8937 & \\
\hline $\mathrm{BD}$ & 14.36 & 1 & 14.36 & 3.65 & 0.0769 & \\
\hline $\mathrm{CD}$ & 26.32 & 1 & 26.32 & 6.68 & 0.0216 & \\
\hline $\mathrm{A}^{2}$ & 51.28 & 1 & 51.28 & 13.01 & 0.0029 & \\
\hline $\mathrm{B}^{2}$ & 349.62 & 1 & 349.62 & 88.73 & $<0.0001$ & \\
\hline $\mathrm{C}^{2}$ & 127.18 & 1 & 127.18 & 32.28 & $<0.0001$ & \\
\hline $\mathrm{D}^{2}$ & 47.13 & 1 & 47.13 & 11.96 & 0.0038 & \\
\hline Residual & 55.16 & 14 & 3.94 & & & \\
\hline Lack of Fit & 40.32 & 10 & 4.03 & 1.09 & 0.5108 & not significant \\
\hline Pure Error & 14.85 & 4 & 3.71 & & & \\
\hline Cor Total & 1507.52 & 28 & & & & \\
\hline
\end{tabular}

Std. Dev $=1.99$, Mean $=24.32, \mathrm{R}^{2}=0.9634$, Adjusted $\mathrm{R}^{2}=0.9268$, Predicted $\mathrm{R}^{2}=0.8306$, Adeq Precision $=18.6432$, C.V. $\%=8.16$.

normal probability versus studentized residuals which was used to check normality of results, all the resultant points of experiments are arranged on the continuous diagonal line this is due to the lack of obvious design normality problems.Studentized residuals and predicted dye yield values of coconut husk are plotted in figure $1 \mathrm{~B}$, shows randomly scattered variance with good dispersion within the accepted range indicates that all response values have constant significant variability. The model adequacy is estimated by comparing experimental and predicted values on the diagonal line in a plot of actual vs. predicted values as shown in Figure 1C. As all the points are close to the straight diagonal line, it could be said that there is a significant agreement between the actual experimental values and the predicted values.

3.2 3D Surface plots depicting the interaction between experimental variables and response Dye yield

3D graph shows the correlation between temperature and $\mathrm{M}: \mathrm{L}$ ratio i.e. solvent ratio on dye yield as shown in Figure 2A. The dye yield increases as the temperature increased from 50 to $80{ }^{\circ} \mathrm{C}$ and slightly decreased when the temperature increase from 80 to $90{ }^{\circ} \mathrm{C}$ as shown in figure $2 \mathrm{D}$. This is due to the increase in temperature the density of the solvent is changed which decreases the solubility of coloring compound, therefore, reduces dye yield (Sundari, 2015). The desired dye yield should contain polyphenols which are abundant coloring compounds in the material. As the material is fibrous coconut husk which is thick and made up of cellulose and polyphenols such as lignin the temperature as experimental variable was kept from 50 to $90{ }^{\circ} \mathrm{C}$. The high temperature degrades and unstabilize the desired polyphenol compounds. Opposite to this the low temperature slows downs the color extraction (Berhanu \& Ratnapandian, 2017; Khoo et al., 2017). This material also occupies the space and hold high amount of water so, the solvent ratio is kept from 1:100 to 1:200. Roughly the observation shows the percentage yield remains constant throughout the range for differential M:L ratio. The mere observation of graphs in Figure $2 \mathrm{~A}$ shows that the temperature at $75^{\circ} \mathrm{C}$ along with the solvent quantity of 1:150 results high percent dye yield.

Figure $2 \mathrm{C}$ describes the interaction between the time and the M:L ratio. The percent dye yield increase as the time increases from 120 to $300 \mathrm{~min}$. As the contact time with the material along with the increasing temperature, the extraction rate of coloring compounds in the solvent system gets increased (Zhang et al., 2018). 

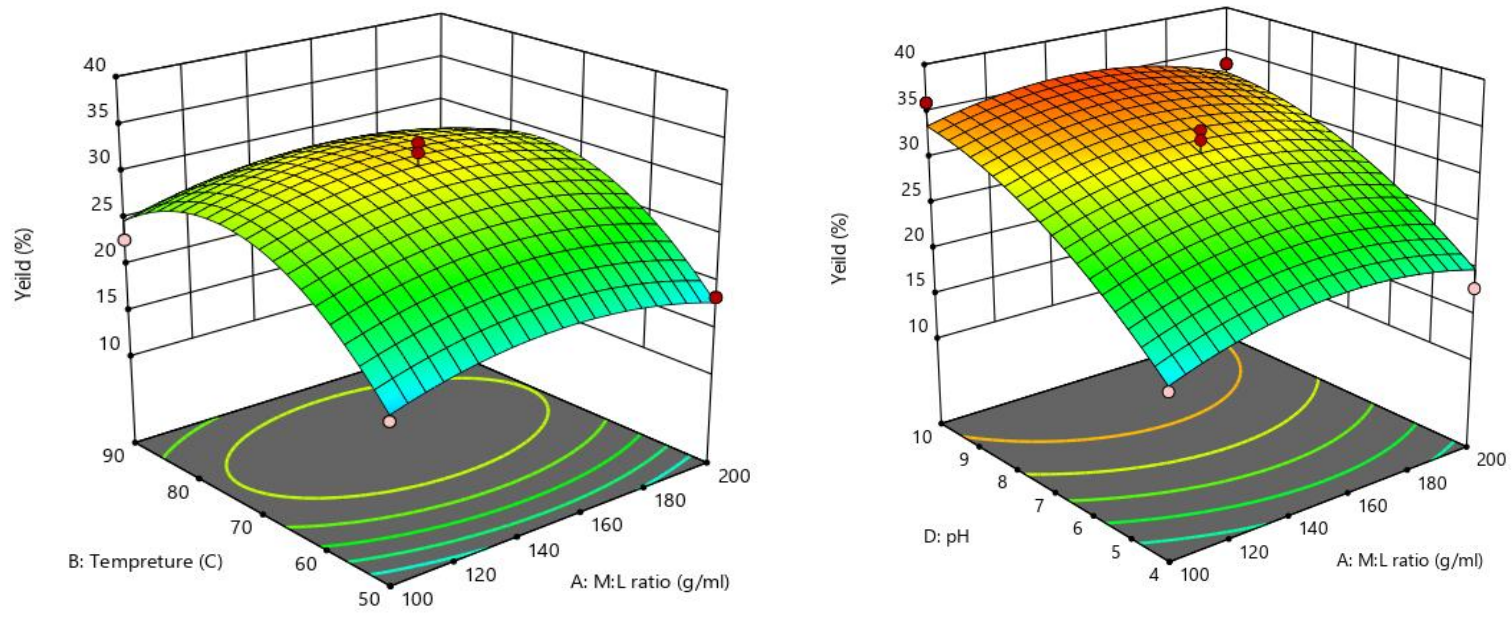

(B)
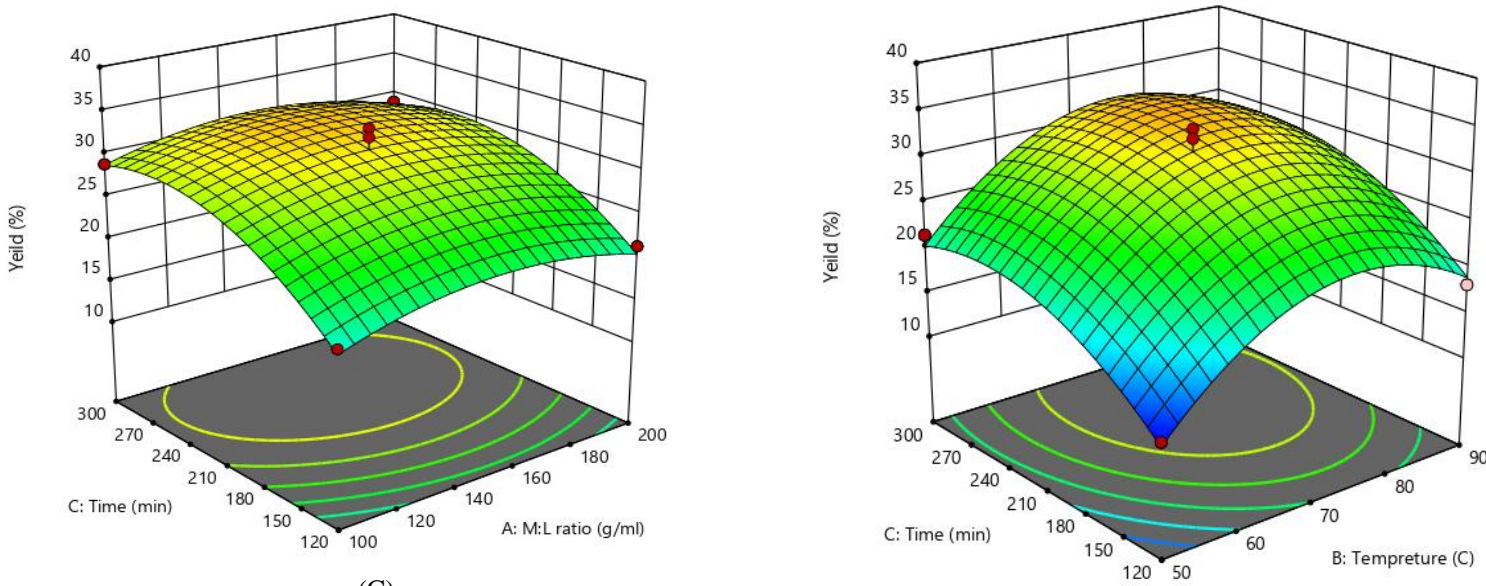

(C)

(D)

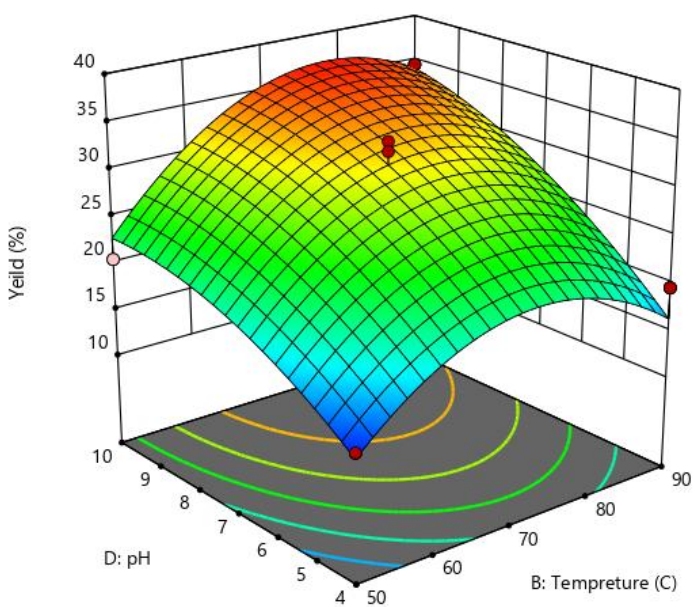

(E)

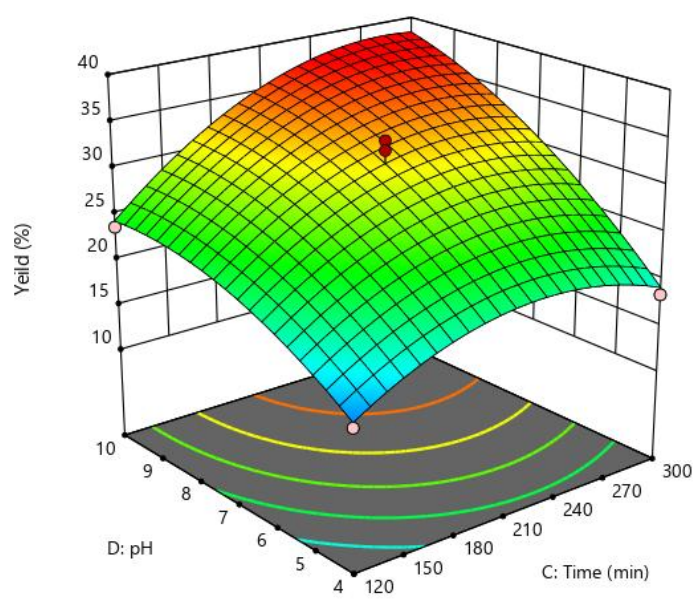

(F)

Figure 2. 3D Surface plots depictingEffect of (A) Temperature and M:L ratio, (B) $\mathrm{pH}$ and M:L ratio (C) Time and M:L ratio (D) Time and Temperature (E) $\mathrm{pH}$ and Temperature $(\mathrm{F}) \mathrm{pH}$ and Time on response $\%$ dye yield.

Journal of Experimental Biology and Agricultural Sciences http://www.jebas.org 
The graph in the figure $2(\mathrm{~B}, \mathrm{E}$ and $\mathrm{F})$ shows that the dye yield increase as the $\mathrm{pH}$ is increased from 4 to 10 . Therefore $\mathrm{pH}$ is an important factor for the increase in dye yield. This indicates that the material is rich in phenolic compounds (Saxena \& Raja, 2014). Although in previous study, it has been observed that the original $\mathrm{pH}$ in distilled water was found to be 6.4 (Israel et al., 2011). Thus, the different hues were obtained in different $\mathrm{pH}$ solutions from 4 to 10. The solutions of different $\mathrm{pH}$ were used to determine the percent dye yield from material. Here, darkness of brown color shade was improved as the $\mathrm{pH}$ is increased from 4 to 10

\subsection{Optimization:}

The optimization function in the system searches different combinations of factor levels that simultaneously fulfill the requirements imposed for each factor and response. Here, for the optimization of factors, a numerical optimization method was used. In which goal for all the factors was kept in range, and for the response it was kept at maximizing level. The weight assigned for the response was 1 which forms a linear ramp function between lower value and the goal, and the importance was set to 5 pluses as the study was done to increase percent dye yield. From the resultant solutions top best solution was used as the optimum values for extraction as depicted in figures 3 (AlAlwani et al., 2016).
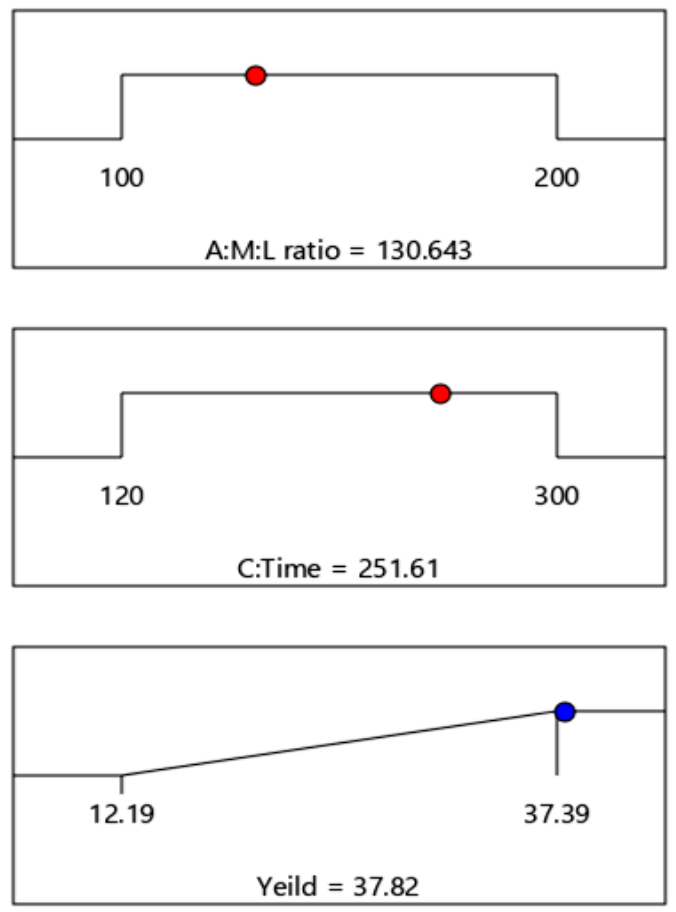

Figure 3.Ramps showing optimal experimental conditions for dye extraction
For acidic to neutral $\mathrm{pH}$, rich brown shade was obtained so the optimized values for this were also calculated by keeping $\mathrm{pH}$ range from 4 to 7 as shown in Figures 4. Further the experiments were conducted under the optimal predicted conditions with a percentage dye yield of 37.39, M:L ratio of 130.64, with extracting temperature of 80.02 for time 251.61 and at $\mathrm{pH} 9.30$ as shown in figure 3. The experiments were also conducted for optimal predicted conditions given for acidic neutral $\mathrm{pH}$ with a percentage dye yield of $33.05, \mathrm{M}: \mathrm{L}$ ratio of 150.54 , with extracting temperature of 75.17 for time 255.15 and at $\mathrm{pH} 7$ as shown in figure 4.

\section{Conclusion}

In present research, four factors $\mathrm{M}: \mathrm{L}$ ratio, temperature, time and $\mathrm{pH}$ were optimized effectively using RSM based Box-Behnken method and the dye yield was improved up to $37 \%$. The ANOVA showing an F-value of 26.33 implies the model is significant and a high correlation coefficient value $\mathrm{R}^{2}$ of 0.9604 confirms that decent fit of model. The optimized values obtained by the model approximately were $M: L$ ratio of $1: 130$, temperature $80^{\circ} \mathrm{C}$, time 250 minutes, $\mathrm{pH} 9.3$ and the optimized values acidic neutral $\mathrm{pH}$ were M:L ratio of $1: 150$, the temperature of $75^{\circ} \mathrm{C}$, time 255 minutes and $\mathrm{pH}$ 7. The yield obtained for acidic-neutral $\mathrm{pH}$ extraction of $33 \%$ was also found to be convincing to extract
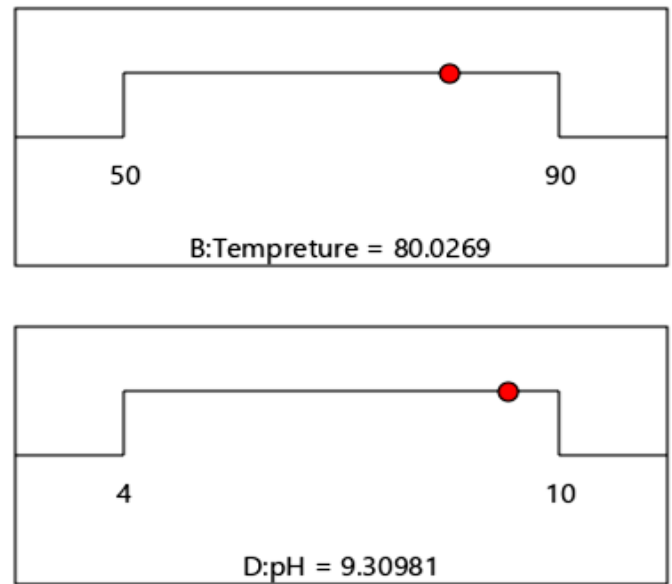

Journal of Experimental Biology and Agricultural Sciences http://www.jebas.org 

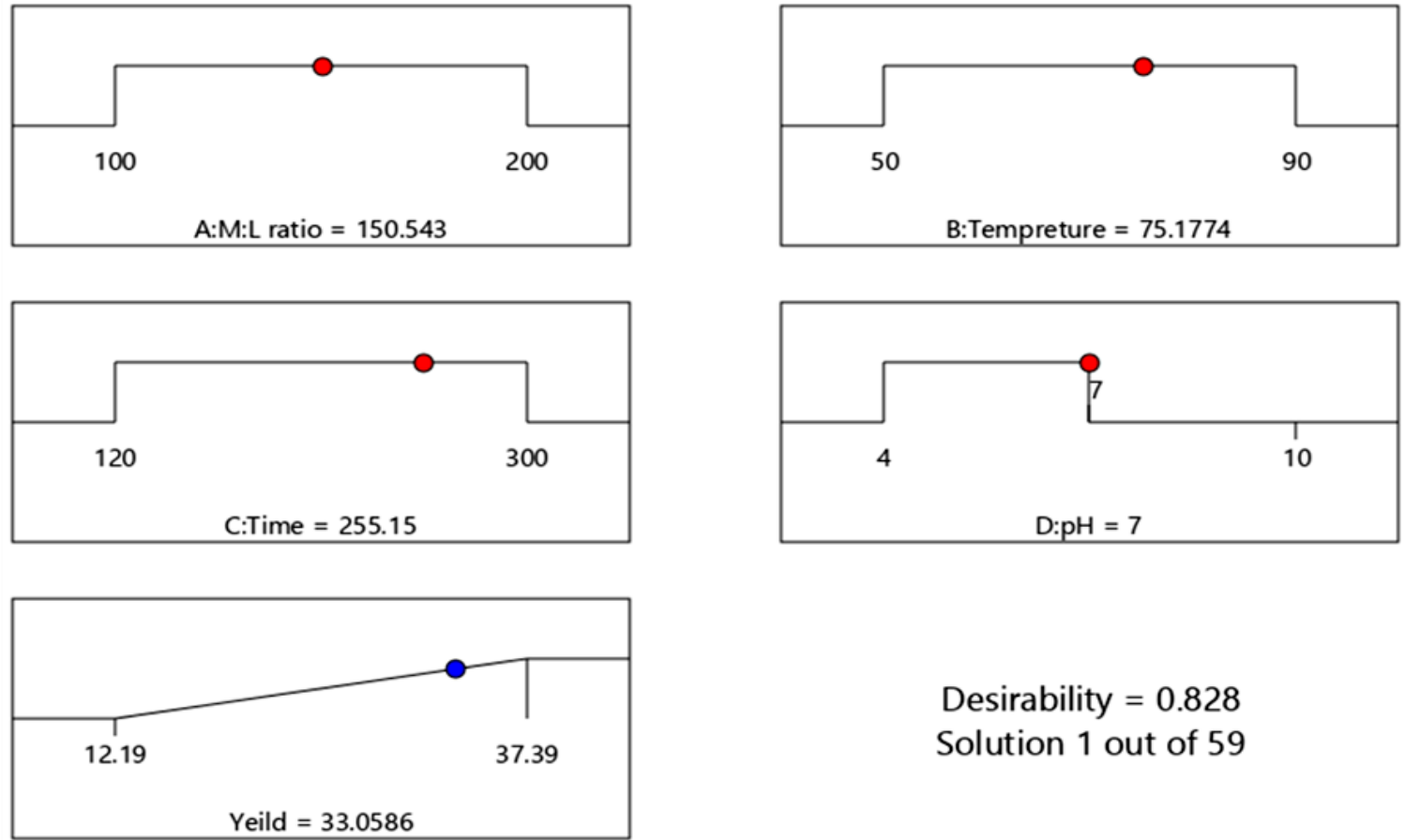

\section{Desirability $=0.828$ \\ Solution 1 out of 59}

Figure 4 Ramps showing optimal dye extraction conditions for $\mathrm{pH} 4$ to 7

different brown color shade. Thus, different hues can be obtained from coconut husk depending upon different $\mathrm{pH}$. Overall the high percent yield shows that the coconut husk is the valuable source of natural dye, it is easily available and shows a good quality use of waste material and thus this dye might be used in wide applications from food to textile industries.

\section{Acknowledgment}

The authors are thankful to the Department of botany Shivaji University, Kolhapur for providing necessary research facilities and Council of scientific and industrial research (CSIR) for Junior Research Fellowship (JRF).

\section{Compliance with Ethical Standards}

Conflict of interest: The authors declare no conflict of interest.

\section{References}

Al-Alwani MAM, Ludin NA, Mohamad AB, Kadhum, Abd AH, Baabbad MM, Sopian K (2016) Optimization of dye extraction from Cordyline fruticosa via response surface methodology to produce a natural sensitizer for dye-sensitized solar cells. Results in Physics 6: 520-529. https://doi.org/10.1016/j.rinp.2016.08.013
Ali S, Jabeen S, Hussain T, Noor S, Siddiqua UH (2016) Optimization of extraction condition of natural dye from pomegranate peels using response surface methodology. International Journal of Engineering Sciences and Research Technology 5: 542-548.

Berhanu T, Ratnapandian S (2017) Extraction and Optimization of Natural Dye from Hambo Hambo (Cassia singueana) Plant Used for Coloration of Tanned Leather Materials. Advances in Materials Science and Engineering 2017, 1-5. https://doi.org/10.1155/2017/7516409

Cáceres A, Girón LM, Alvarado SR, Torres MF (1987) Screening of antimicrobial activity of plants popularly used in guatemala for the treatment of dermatomucosal diseases. Journal of Ethnopharmacology 20: 223-237. https://doi.org/10.1016/03788741(87)90050-X

Esquenazi D, Wigg MD, Miranda MMFS, Rodrigues HM, Tostes JBF, Rozental S, da Silva AJR, Alviano CS (2002) Antimicrobial and antiviral activities of polyphenolics from Cocos nucifera Linn. (Palmae) husk fiber extract. Research in Microbiology 153: 647652. https://doi.org/10.1016/s0923-2508(02)01377-3

Freitas JCC, Nunes-Pinheiro DCS, Pessoa AWP, Silva LCR, Girão VCC, Lopes-Neto BE, Agostinho MS, Abreu CRA (2011) Effect 
of ethyl acetate extract from husk fiber water of Cocos nucifera in Leishmania braziliensis infected hamsters. Revista Brasileira de Farmacognosia 21: 1006-1011. https://doi.org/10.1590/S0102695X2011005000138

Gupta D, Khare SK, Laha A (2004) Antimicrobial properties of natural dyes against Gram-negative bacteria. Coloration Technology 120: 167-171. https://doi.org/10.1111/j.14784408.2004.tb00224.x

Hope BE, Massey DG, Fournier-Massey G (1993) Hawaiian materia medica for asthma. Hawaii Medical Journal 52: 160-166.

Imo C, Ezeonu CS, Glory Imo N, Anigbo CJ (2018) Proximate, Mineral and Phytochemical Composition of Cocos nucifera Nut Asian Journal of Biochemistry 13: 9-14 https://doi.org/10.3923/ajb.2018.9.14

Israel AU, Ogali RE, Akaranta O, Obot IB (2011) Extraction and characterization of coconut (Cocos nucifera L.) coir dust 9.

Jabeen S, Ali S, Nadeem M, Arif K, Qureshi N, Shar G, Soomro G, Iqbal M., Nazir A, Siddiqua, UH (2019) Statistical Modeling for the Extraction of Dye fromNatural Source and Industrial Applications. Polish Journal of Environmental Studies 28: 21452150. https://doi.org/10.15244/pjoes/85125

Khalid Thebo N, Ahmed Simair A, Sughra Mangrio G, Ansari K, Ali Bhutto A, Lu C, Ali Sheikh W (2016) Antifungal Potential and Antioxidant Efficacy in the Shell Extract of Cocos nucifera (L.) (Arecaceae) against Pathogenic Dermal Mycosis. Medicines 3: 12. https://doi.org/10.3390/medicines3020012

Khoo HE, Azlan A, Tang ST, Lim SM (2017) Anthocyanidins and anthocyanins: colored pigments as food, pharmaceutical ingredients, and the potential health benefits. Food \& Nutrition Research 61: 1361779. https://doi.org/10.1080/16546628.2017.1361779

Lima EBC, Sousa CNS, Meneses LN, Ximenes NC, Santos Júnior MA, Vasconcelos GS, Lima NBC, Patrocínio MCA, Macedo D, Vasconcelos SMM (2015) Cocos nucifera (L.) (Arecaceae): A phytochemical and pharmacological review. Brazilian Journal of Medical and Biological Research 48: 953-964. https://doi.org/10.1590/1414-431x20154773

Matos FJA (1997) Introdução à fitoquímica experimental. Edições UFC, Fortaleza.
Mitchell SA, Ahmad MH (2006) A review of medicinal plant research at the University of the West Indies, Jamaica, 1948-2001. West Indian Medical Journal 55: 243-269. https://doi.org/10.1590/s0043-31442006000400008

Pal D, Sarkar A, Gain S, Jana S, Mandal S (2011) CNS DEPRESSANT ACTIVITIES OF ROOTS OF COCCOS NUCIFERA IN MICE 6

Renjith R, Chikku A, Rajamohan T (2013) Cytoprotective, antihyperglycemic and phytochemical properties of Cocos nucifera (L.) inflorescence. Asian Pacific Journal of Tropical Medicine 6: 804-810. https://doi.org/10.1016/S1995-7645(13)60142-X

Saxena S, Raja ASM (2014) Natural Dyes: Sources, Chemistry, Application and Sustainability Issues, in: Muthu SS (Ed.), Roadmap to Sustainable Textiles and Clothing. Springer Singapore, Singapore, pp. 37-80. https://doi.org/10.1007/978-981287-065-0_2

Segurola J, Allen NS, Edge M, Mc Mahon A (1999) Design of eutectic photoinitiator blends for UV/visible curable acrylated printing inks and coatings. Progress in Organic Coatings 37: $23-$ 37. https://doi.org/10.1016/S0300-9440(99)00052-1

Sundari N (2015) Extraction and optimization of Mucuna pruriens for dyeing of leather. Polish Journal of Chemical Technology 17: 57-63. https://doi.org/10.1515/pjct-2015-0030

Tayeb AM, Tony MA, Mansour SA (2018) Application of BoxBehnken factorial design for parameters optimization of basic dye removal using nano-hematite photo-Fenton tool. Applied Water Science 8: 138. https://doi.org/10.1007/s13201-018-0783-x

Verma D, Fortunati E, Jain S, Zhang X (Eds.) (2019) Biomass, biopolymer-based materials, and bioenergy: construction, biomedical, and other industrial applications, Woodhead Publishing series in composites science and engineering. Woodhead Publishing, Duxford Cambridge Kidlington.

Zhang QW, Lin LG, Ye WC (2018) Techniques for extraction and isolation of natural products: a comprehensive review. Chinese Medicine 13: 20. https://doi.org/10.1186/s13020-018-0177-x

Zollinger H (2003) Color chemistry: syntheses, properties, and applications of organic dyes and pigments, 3., rev. ed. ed. Verl. Helvetica Chimica Acta, Zürich. 